ANÁLISIS [ ISSN: 0120-8454 [ Vol. 49 / No. 90 [ Bogotá, ene.-jun. / 2017 [ pp. 63-82

\title{
Sasañan: migraciones, investigaciones y autorreflexividades. Consideraciones preliminares*
}

\author{
Angélica Paola Alvites Baiadera* \\ Rosa Elizabeth Quiroga Saavedra**
}

Recibido: 29 de agosto de 2016 -Aprobado: 28 de septiembre de 2016

\section{Resumen}

A partir de nuestras investigaciones, trabajos etnográficos y de campo sobre migraciones bolivianas y peruanas en Córdoba, Argentina, proponemos detenernos en el análisis de un momento necesario en todo proceso investigativo: la autorreflexividad como investigadoras. Así, nuestra posición como migrante e hija de migrante que estudia las migraciones nos permite comprender que la sola presencia en los ámbitos que decidimos investigar son toda una definición (Guber, 2014). Primero, trabajamos sobre nuestra caja de herramientas analíticas; luego, analizamos nuestras propias experiencias como investigadoras, como migrante o hija de migrante, y, por último, exponemos algunos hallazgos y conclusiones finales que resaltan la imposibilidad y, por lo tanto, la necesidad de trascender el dualismo entre el sujeto que investiga y el objeto investigado. Todo ello, sin negar u olvidar las diferencias y desigualdades que existen entre las cientistas y los grupos estudiados, así como la constate tensión entre apuestas, disposiciones e intenciones que exceden el campo científico.

Palabras clave: autorreflexividad, investigación, migración, trabajo de campo.

\footnotetext{
Sasañan, en quechua, significa 'camino difícil' (Laime Ajacopa, 2002) Un trabajo preliminar se presentó en el II Simposio Internacional Sobre Estudios Latinoamericanos: Diálogos interdisciplinarios sobre sociedad, historia, cultura, frontera y territorio (antropología, historia, ciencias sociales, geografía, música popular) y en el Primer Seminario Grupo de Estudios Históricos, organizados por la Universidad Nacional de Villa María, en agosto de 2015. Artículo de reflexión. El texto es, en parte, producto de nuestras tesis doctorales en proceso. Para el desarrollo de sus producciones cada autora es financiada por Conicet y SecyT-UNC, respectivamente. DOI: http://dx.doi.org/10.15332/s0120-8454.2017.0090.03

* Becaria del Consejo Nacional de Investigaciones Científicas y Técnica de Argentina. Centro de Estudios Avanzados de la Universidad Nacional de Córdoba (CEA-UNC). Doctoranda en Ciencia Política del CEA-UNC. Licenciada en Sociología por la Universidad Nacional de Villa María. Correo electrónico: angelalvites@yahoo.com.ar

** Becaria de la Secretaría de Ciencia y Tecnología, Universidad Nacional de Córdoba (UNC). Doctoranda en Ciencias Antropológicas de la Facultad de Filosofía y Humanidades (UNC), Instituto de Antropología de Córdoba (IDACOR). Museo de Antropología de dicha universidad. Licenciada en Psicología, Universidad Mayor de San Simón, Cochabamba, Bolivia. Correo electrónico: paquara@gmail.com
} 


\title{
Sasañan: migrations, research and self-reflexivity Preliminary considerations*
}

\author{
Angélica Paola Alvites Baiadera** \\ Rosa Elizabeth Quiroga Saavedra***
}

A bstract

Based on our research, ethnographic field's work on Bolivian and Peruvian migration in Córdoba, Argentina, we propose to dwell on the analysis of selfreflexivity as researchers. We understand self-reflexivity as all necessary investigative process. Considering our positions (a migrant and a migrant's daughter studying migrations), we understand that our mere presence in the areas we decided to investigate is a definition itself (Guber, 2014). First, we work on our box of analytical tools; later, we discuss our own experiences as researchers, as a migrant, and as a migrant's daughter. Finally, we bring some findings and conclusions that highlight the impossibility, and therefore, the need to transcend the dualism between the subject that investigates and the investigated object. This, without denying the differences and inequalities between scientists and study groups as well as the constant tension between bets, dispositions and intentions that exceed the scientific field.

Keywords: Self-reflexivity, migration, research, fieldwork.

Sasañan, in Quechua, means 'difficult road' (Laime Ajacopa, 2002). A preliminary work was presented at the II International Symposium on Latin American Studies: Interdisciplinary Dialogues on society, history, culture, frontier and territory (anthropology, history, social sciences, geography, folk music) and at the First Seminar Group of Historical Studies, by the National University of Villa Maria, in August 2015. Reflection article. The paper is, in part, product of the authors' ongoing doctoral thesis. For the development of their products each author is financed by Conicet and SecyT-UNC, respectively. DOI: http://dx.doi.org/10.15332/s0120-8454.2017.0090.03

* Fellow of the National Council of Scientific and Technical Research of Argentina. Center for Advanced Studies of the National University of Cordoba (CEA-UNC). PhD in Political Science of CEA-UNC. Degree in Sociology from the National University of Villa María. Email: angelalvites@yahoo.com.ar

** Fellow of the Secretary of Science and Technology, National University of Cordoba (UNC). PhD in Anthropological Sciences of the Faculty of Philosophy and Humanities (UNC), Institute of Anthropology of Cordoba (IDACOR). Museum of Anthropology of the same university. Degree in Psychology, University of San Simón, Cochabamba, Bolivia. Email: paquara@gmail.com 


\title{
Sasañan: migrations, recherches et autoréflexivités. Considérations préliminaires*
}

\author{
Angélica Paola Alvites Baiadera** \\ Rosa Elizabeth Quiroga Saavedra**
}

\section{Résumé}

À partir de nos recherches, de nos travaux ethnographiques et sur le terrain au sujet des migrations boliviennes et péruviennes à Córdoba, en Argentine, nous proposons de nous arrêter dans l'analyse d'un moment nécessaire dans tout processus de recherche: l'autoréflexivité comme chercheuses. Ainsi, notre position comme migrante et fille de migrante qui étudie les migrations nous permet de comprendre que la seule présence dans les domaines sur lesquels nous décidons d'enquêter est toute une définition (Guber, 2014). D'abord, nous travaillons sur notre caisse à outils analytiques; ensuite, nous analysons nos propres expériences comme chercheuses, comme migrante ou fille de migrante, et, finalement, nous exposons quelques découvertes et conclusions finales qui soulignent l'impossibilité et, par conséquent, le besoin de dépasser le dualisme entre le sujet qui enquête et l'objet enquêté. Tout cela, sans nier ou sans oublier les différences et les inégalités qui existent entre les sociologues et les groupes étudiés, ainsi que la constante tension entre paris, dispositions et intentions qui excèdent le champ scientifique.

Mots clés: Autoréflexivité, recherche, migration, travail de champ.

Sasañan, en langue quechua, signifie 'chemin difficile' (Laime Ajacopa, 2002). Un travail préliminaire fut présenté pendant le II Colloque International sur les Études Latino-américaines: Dialogues interdisciplinaires sur la société, histoire, culture, frontière et territoire (anthropologie, histoire, sciences sociales, géographie, musique populaire) et pendant le Premier Séminaire Groupe d'Études Historiques, organisés par l'Université Nationale de Villa María, en août 2015. Article de réflexion. Le texte est, en partie, produit de nos thèses doctorales en procès. Pour le développement de leurs productions chaque auteur est financée par Conicet et SecyT-UNC, respectivement. DOI: http://dx.doi.org/10.15332/ s0120-8454.2017.0090.03

* Boursière du Conseil National des Recherches Scientifiques et Technique d'Argentine. Centre d'Études Avancées de I'Université Nationale de Córdoba (CEA-UNC). Doctorante en Science Politique du CEA-UNC. Licenciée en Sociologie par l'Université Nationale de Villa María. Email: angelalvites@yahoo.com.ar

*.- Boursière du Secrétariat de Science et de Technologie, Université Nationale de Córdoba (UNC). Doctorante en Sciences Anthropologiques de la Faculté de Philosophie et d'Humanité (UNC), I'Institut d'Anthropologie de Córdoba (IDACOR). Musée d'Anthropologie de la dite université. Licenciée en Psychologie, Université Mayor de San Simón Cochabamba, Bolivie.Email: paquara@gmail.com 
De vez en cuando hay que hacer/ una pausa contemplarse a sí mismo/sin la fruición cotidiana examinar el pasado/rubro por rubrol etapa por etapa/baldosa por baldosa y no llorarse las mentiras/sino cantarse las verdades.

Mario Benedetti, Inventario 2, 1985

\section{Inquietudes que nos impulsan a escribir}

Este escrito es reflejo de encuentros cara a cara, algunos acompañados con mates ${ }^{1}$ de por medio, y otros por internet, en los cuales discutíamos sobre nuestras experiencias en el trabajo de campo. Estos momentos nos permitían intercambiar algunas incertidumbres e inquietudes no solo respecto al trabajo académico, sino también sobre nuestras experiencias personales como migrantes e hijas de migrantes que estudian procesos migratorios, nuestros viajes, nuestros lugares y no-lugares.

Inicialmente, esos distintos encuentros no estaban pensados ni fueron planificados para realizar un escrito, pero un día decidimos darle forma a todas esas charlas ${ }^{2}$. Más allá de nuestras distintas formaciones iníciales y de posgrado, cuando reflexionábamos sobre nuestras experiencias investigativas "algo nos conectaba". Encontramos a través de la antropología una herramienta - la reflexividad que nos permitía comprender esa conexión.

Nos proponemos trabajar en este artículo la autorreflexividad como investigadoras, pues comprendemos que nuestra sola presencia en los ámbitos que decidimos investigar son toda una definición (Guber, 2014). "Un lugar" que, a nuestro entender, nos hace transitar diversos momentos en el proceso investigativo: desde dónde nos preguntamos, cómo ponemos en juego nuestras posiciones como migrante e hija de migrante estudiando migraciones.

Si bien se considera que los momentos de autorreflexividad suelen escribirse, sobre todo al finalizar un trabajo concreto de investigación, consideramos significativo trascribir nuestros sasañan en el proceso. Es decir, partiendo de nuestras investigaciones, de nuestros trabajos etnográficos y de campo, atravesados

1 El mate es una infusión hecha con hojas de yerba mate, planta originaria de las cuencas de los ríos Paraná, Paraguay y el curso superior del Uruguay. Los pueblos guaraníes la consumían en épocas anteriores a la colonia española y portuguesa (y por la influencia de aquellos, otros pueblos también adquirieron la costumbre, como es el caso de los querandíes, los pampas antiguos y los qoms, entre otros). Tal infusión, con diferentes variantes, se mantuvo después de la colonia, y hoy es parte de las costumbres de toda Argentina, Paraguay y Uruguay, y de algunas zonas de Brasil, Chile y Bolivia (principalmente, en Tarija, Santa Cruz y Chuquisaca).

2 Agradecemos a nuestros directores de tesis y a nuestros compañeros de investigación, por leernos, escucharnos y criticarnos. Nuestro especial agradecimiento a Silvia Rivera Cusicansqui, Cynthia Pizarro, Lourdes Saavedra, Eduardo Domenech, Hugo Córdova Quero y Fernanda Stang. 
por nuestras experiencias, en torno a las migraciones bolivianas y peruanas en Córdoba Argentina.

Este escrito nos permite visibilizar(nos) de diversas maneras, pues haber migrado, o ser hija de personas que migraron, nos posiciona en lugares de diferencias, de disputas, de interpelaciones y de miradas a la hora de construir nuestras herramientas analíticas. Cómo una enuncia, cómo una narra, cómo una traduce ciertos sucesos no solo transmite información sobre los acontecimientos, sino también construye contextos en el cual esa información puede cobrar algún sentido.

Este registro (a nuestro entender) necesario, surge a partir de una preocupación latente en nuestras investigaciones: el miedo a cometer aquel etnocentrismo que criticamos "en el papel" y que después "en la práctica" podemos reproducir "inconscientemente".

En palabras de Puwar (2008), tratamos de preguntarnos cuáles son las catexis que cómo académicas ponemos en juego en las construcciones que fabricamos y qué posiciones adoptamos frente a ellas.

Este escrito pretende sumar a las reflexiones la necesidad de estar alerta a nuestras propias prácticas como investigadoras, para no caer en aquellas composiciones que oscilan entre la victimización, la heroicidad, el esencialismo, la compasión o la glorificación de los sujetos migrantes. O en palabras de Grignon y Passeron (1991) ser capaces de sortear posiciones relativistas y legitimistas.

Comprendemos que estas inquietudes pueden ser "comunes" a todo proceso de investigación, mas la transcripción "en papel" implica dejar registro con miras a vigilar las representaciones que construimos sobre los sujetos que estudiamos y sobre las categorías que inventamos (es decir, cómo nos posicionamos) ${ }^{3}$.

Para trabajar estas inquietudes, presentamos inicialmente nuestra caja de herramientas analítica; posteriormente analizamos nuestras propias experiencias en relación/tensión con las investigaciones que estamos llevando a cabo en torno a las migraciones de bolivianos y peruanos en Córdoba. Para arribar, por último, a algunos hallazgos y conclusiones (preliminares) que resaltan la imposibilidad, y por lo tanto, la necesidad de trascender el dualismo entre "sujeto" que investiga y "objeto" investigado. Sin negar ni olvidar las diferencias y desigualdades entre las investigadoras y los grupos estudiados. En este sentido, comprendemos que la tarea académica se encuentra en constate tensión entre apuestas, disposiciones e intenciones que exceden el campo científico.

3 El registro cobra diversos sentidos, pues está sujeto a los distintos momentos de la investigación. 


\section{Nuestra caja de herramientas ${ }^{4}$}

En las ciencias sociales se establecen ciertas divisiones del trabajo científico a partir de la segunda mitad del siglo XX; el cual hoy, de cierto modo, seguimos habitando. En términos de Lander (2005), en las ciencias sociales se construye una división que separa entre pasado y presente ${ }^{5}$ y se delimitan campos diferenciados entre lo social, lo político y lo económico ${ }^{6}$. Donde la discusión sobre reflexividad, como parte del proceso de investigación (véase Guber, 2014), ha sido propiamente antropológica. Sin embargo, más allá de esta división históricamente construida las fronteras entre aquellas se encuentran porosas y en disputa. Esta división disciplinar obtura la posibilidad de reconocer la autorreflexividad como parte del proceso que como cientificistas sociales tenemos que transitar.

Silvia Rivera Cusicanqui (2010) intenta superar esta división disciplinar, interviniendo desde lugares más plurales, nos propone indagar sobre nuestras propias prácticas reflexionando desde la historia oral y las memorias sociales y colectivas. Por su parte, Rosana Guber (2014), nos invita a comprender dónde, cuándo, cómo y porqué un investigador escribe lo que escribe (Guber, 2014), dándonos pistas para entender los modos en que como estudiosas "conquistamos" para nosotras una posición de sujeto/a a través de las diversas construcciones que hacemos del otro.

Investigar requiere de ciertas prácticas que aprendemos en el transcurrir del ejercicio académico, entre la literatura sobre investigaciones y en el trabajo de campo. Donde las subjetividades de los investigadores y de los demás sujetos implicados son parte de la misma, siendo necesario dejar registro sobre las "idas y vueltas" del proceso de investigación". De este modo, "Las [auto] reflexiones sobre [la]s acciones, observaciones, sentimientos, [conflictos], impresiones en el campo se trasforman en datos, forman[do] parte de la interpretación y son documentados en diarios de investigación" (Vasilachis de Gialdino, 2006, p. 27).

4 Caja de herramientas como interpretación de los diversos recursos analíticos y no como un sistema, una teoría completa y cerrada. Herramientas que se encuentran dentro de una "lógica propia a las relaciones de poder y a las luchas que se comprometen alrededor de ellas: que esta búsqueda no puede hacerse más que poco a poco, a partir de una reflexión (necesariamente histórica en algunas dimensiones) sobre situaciones dadas" (Foucault, 2009, p. 173). En este sentido, no intentamos construir un sistema teórico completo y acabado, sino encontrar instrumentos que nos posibiliten repensar las lógicas que intentamos trabajar. Así, tomamos los distintos vértices o aristas no como metanarrativas ni como puntos de vista objetivos que nos garanticen la verdad; en vez de principios universales, de conceptos casi autónomos que se concretan de modo empírico o no, proponemos pensar las categorías como referentes producidos en el contexto.

5 De este modo, "la disciplina historia estudia el pasado, mientras se definen otras especialidades que corresponden al estudio del presente" (Lander, 2005, p. 20).

6 En las ciencias sociales se delimitan campos "concebidos [...] como regiones ontológicas de la realidad histórico-social" (Lander, 2005, p. 21). A cada uno de estos ámbitos le corresponde "una disciplina de las ciencias sociales, con su objeto de estudio, sus métodos, sus tradiciones intelectuales, sus departamentos universitarios: la sociología, la ciencia política y la economía. La antropología y los estudios clásicos se definen como los campos para el estudio de los otros" (p. 2).

7 Según Tsuda, desde una perspective psicosocial, "Anthropologists in the past have relied on the theoretical frameworks they use to analyze ethnographic materials to self-reflexively understand the fieldwork process itself. [...] A number of researchers have discussed the relationship between the anthropologist's evolving sense of identity and the fieldwork process (Kondo, 1986, 1990; Myerhoff y Ruby, 1982; Whitehead y Conaway, 1986)" (1998, p. 109). 
Asimismo, comprendemos que no tenemos que producir listas exhaustivas, "notas confesionales de campo antes de presentar los desordenados textos del Otro, con un pleno reconocimiento de la función de injerencia desempeñada por el estudioso. Por consiguiente, tenemos al ojo epistémico omnisciente atribulado y en apuros" (Puwar, 2008, p. 252).

Desde la reflexividad, se entiende que las descripciones y afirmaciones son constitutivas de la realidad, y esta se entiende como la íntima relación entre comprender/interpretar y expresar no solo una situación particular, sino también cómo se la constituye y define (Guber, 2011). (Aunque parezca una obviedad, a estas alturas, en necesario recordarnos que el trabajo de campo se constituye con las "personas adentro", con sus historias, con las urgencias "del día a día" y con las relaciones que se construyen con las investigadoras).

Interpretar el proceso de construcción académica desde la reflexividad (y la autorreflexividad en este artículo) nos permite un tratamiento de los sucesos que protagonizamos, escuchamos y construimos en el trabajo de campo, pudiendo acceder de forma analítica a "las condiciones en que conocemos y producimos conocimiento y el modo en que esa producción es interpretada por nuestros sujetos de estudio" (Colabella, 2014, p. 90).

En muchas investigaciones lo que no se pone en evidencia, (ya sea en el proceso o en los resultados) es el lugar desde donde se hacen las interpretaciones. "[La] reflexividad es equivalente a una conciencia del investigador sobre su persona, sus condicionamientos sociales y políticos. Género, edad, pertenencia étnica, clase social y afiliación política [entran en juego]" (Guber, 2011, p. 45).

El "desafío esta en transitar de la reflexividad propia a la de los nativos" (Guber, 2011), para nosotras como investigadoras de las migraciones marcadas por historias migrantes implica un proceso de "introyección", una mirada de nuestras propias historias, construyendo un posicionamiento crítico desde las ciencias y desde nuestras experiencias. Es decir, si la autora plantea la reflexividad desde cierta exterioridad (por decirlo en términos que no utiliza, pero que nos sirven para la aclaración) entre sujetos-objetos, nuestras propias experiencias migrantes, cuestionan esa exterioridad y nos tensionan en el trabajo de campo. Asimismo, como sugiere la autora, entran en juego las reflexividades de nuestros interlocutores, que no por el hecho de que - en parte - nos identifiquen(mos) con ellos las interpretaciones son las mismas que las nuestras.

El hecho mismo de investigar "migración boliviana siendo boliviana" o "migración peruana siendo hija de peruano", ya nos coloca en otro lugar en el proceso de investigación. Tanto desde el acceso al campo hasta nuestras apuestas teóricas: "ni verdaderamente del lado de los mismos, ni totalmente del lado de lo Otro 
[...] no hace[mos] más que reproducir el embarazo que crea [nuestra] molesta existencia" (Bourdieu, 2010, p 16) .

Pues, como propone Zapata (2014), poco se menciona o se trabaja sobre los investigadores denominados halfies, los del medio, los divididos, es decir, sobre "los dilemas espaciales [diríamos especiales] que enfrentan, dilemas que revelan cabalmente los problemas del supuesto de la antropología cultural respecto de la distinción fundamental entre [el] self y [el] otro" (Zapata, 2014, p. 184; cursiva añadida).

\section{Migraciones y autorreflexividades}

La presencia de migrantes limítrofes en Argentina, registrada desde el año 1869 por el primer censo nacional, ha ido en aumento y en las últimas décadas ha tendido a "visibilizarse aún más" (Benencia, 2008 puntualiza esto para el caso peruano $)^{9}$. Diversos autores sostienen que esta "visibilidad" se ha construido y "sobredimensionado". Algunos afirman que esto se debe, en parte, a la disminución de la migración de origen europeo (Doménach y Celton, 1995) y el aumento relativo de la migración regional. Varios, consideran que se debe principalmente a la concentración espacial en las grandes urbes (Montesinos, 2005). Y otros sostienen el papel significativo que juegan los medios de comunicación a la hora de representarlos (Albarracín, 2005).

La mirada acerca de łos migrantes regionales, principalmente bolivianos, paraguayos y peruanos, desde los años 90 - con mayor intensidad - son "blanco" de campañas discriminatorias por parte de algunos sectores de la sociedad civil, los medios de comunicación, los funcionarios de gobierno y los organismos públicos/oficiales. Culpados de la crisis del sistema público de salud, del incremento de la desocupación y de la tan difundida 'explosión delictiva' (Caggiano, 2007, p. 13) ${ }^{10}$.

8 En algún punto, esto refleja cómo la presencia inmigrante es una presencia ilegítima que perturba la supuesta perfección mítica de cierto orden nacional, a la vez que distingue quiénes son nacionales y ciudadanos de aquellos que no lo son (Sayad, citado en Gil Araujo, 2009).

9 La migración proveniente de Perú recién aparece identificada en los últimos cuatro censos nacionales (1980, 1991, 2001 y 2010), ya que al no ser un país limítrofe, se lo incluía en la categoría resto de América del Sur. Es a través de entrevistas que pueden registrarse migraciones de peruanos, de forma regular, desde 1950 o 1560 . En un registro del Instituto Nacional de Estadística y Censos (Indec), de 1996, se desagregaron los datos de los peruanos en los distintos censos (1869: $\sin$ datos; 1895: 551; 1914: 1247; 1947: 2760; 1960: $\sin$ datos; 1970: sin datos; 1980: 8561; 1991: 15.939; 2001: 87.546; 2010: 157.514 peruanos censados).

10 Si bien excede el análisis de este artículo, no es un dato menor que el actual Gobierno nacional, encabezado por Mauricio Macri, realice ciertas cadenas de equivalencias entre fronteras, trata de personas, narcotráfico y extranjeros: «Macri evalúa desde hace un tiempo una reforma a la ley de migraciones y un endurecimiento en los sistemas de control fronterizo. El Ministerio del Interior tiene en carpeta un borrador de un proyecto que prevé esos cambios. Pero el flagelo excede a un ministerio y se necesita la colaboración de varios sectores. El presidente dio muestras de querer reinsertarse en el mundo y mostrar una Argentina más confiable. Pero el caso Pérez Corradi no hace más que remover una película de terror donde las fronteras son aptas para el narcotráfico, la trata de personas o cualquier otra gama de delitos que dejan al país en el ridículo. O peor aún: en condiciones muy vulnerables para el ciudadano común» (Dinatale, 2016). 
De este modo, los movimientos interpelan no solo a los sujetos que se mueven sino también a nivel micro a sus familias, sus afectos y sus redes sociales; a nivel macro a los países, sus políticas, a las regiones de destino y origen. Se trata de un complejo fenómeno multidimensional y por lo tanto, difícil de estudiar.

En este sentido, consideramos que el proceso de reflexividad tiene que recuperar con mayor atención no solo los lugares de origen (Herrera, Carrillo Espinosa, Torres, 2005), sino también articularlos con los lugares de destinos; interpretando el proceso migratorio como un hecho social total (Sayad, 2010). En el que se incluya la historia oral de las personas y los acontecimientos del orden micro que constituye su realidad (Rivera Cusicanqui, 2010).

En este sentido, como académicos ¿cuánto, por ejemplo, y no lo estamos pensando en términos cuantitativos, comprendemos e interpretamos los diversos procesos políticos e históricos de Perú o Bolivia? ¿Cómo estamos construyendo las categorías sociales acerca de los migrantes? Y ¿Cómo recuperamos las trayectorias de los migrantes teniendo en cuenta estos elementos?

Todo estudio de los fenómenos migratorios que descuide las condiciones de origen de los emigrados está condenado a no dar más que una visión, a la vez parcial y etnocéntrica, del fenómeno migratorio; como si, por una parte, su existencia comenzara en el momento en que llega, y, por la otra, la problemática abordada explícita e implícitamente fuera la de la adaptación a la sociedad de “acogida" (Sayad, 2010, p. 56).

Es decir, apostamos a entender a los sujetos no solo como inmigrantes (desde que cruzan una frontera jurídico-política), a partir de sus trayectorias sociales, sus recorridos, sus historias de vida personales y colectivas, sino también como migrantes, pues migrar es movilizarse con historias, experiencias, esperanzas, afectos, nostalgias, recuerdos, es la movilidad de corporalidades sociales. La migración es esa conflictiva relación entre emigración e inmigración.

Para analizar la movilidad, tenemos que comprender a los sujetos en el juego entre emigración-inmigración, y no solo como producto de una suerte de clasificación humana (donde se rotula a ciertas personas que se mueven como inmigrantes y a otras no [De Genova, 2014]). Esto se concatena, por un lado, cuando se da por sentado que los migrantes tienen una identidad - étnicatotalmente diferente a "la identidad" nacional del país de destino:

[...] para muchos compañeros [académicos] se trata de una identidad "mejor" - en la medida en que estaría más enraizada en un tejido "comunitario" - me parece que esa perspectiva reproduce un esquema típico colonial: acá los individuos, allá las comunidades; acá las naciones, allá las "etnias"; acá los ciudadanos, allá los súbditos. (Mezzadra, 2005, pp. 25-26). 
Por el otro, se relaciona en cómo comprendemos a los sujetos migrantes desde el lugar de destino: la imagen del migrante como sujeto débil necesitado de cuidados y de asistencia; y en otros, como un sujeto peligroso "necesitado" de control.

[...] el inmigrado tiene la sensación de ser vigilado permanentemente, como se vigila a un cuerpo extraño; tiene la sensación de haberse convertido en un eterno sospechoso del que cada uno de los hechos y gestos es objeto de una acusación: en la calle y en las tiendas, en la vivienda, en los servicios públicos. (Sayad, 2010, p. 290)

En este sentido, cuando el sujeto que se mueve es solo comprendido en su condición de inmigrado, como débil o sospechoso, se lo anula, se lo obtura, está ausente parte de "su historia" pues solo es interpretado como producto y efecto de la inmigración (un no-nacional). Al mutilar el fenómeno migratorio solo a la inmigración "nos exponemos a constituir a [dicha] población [...] como una simple categoría abstracta y al inmigrado como un puro artefacto" (Sayad, 2010, p. 254).

\section{Autorreflexividad: nuestras experiencias}

Entendemos que el trabajo de campo en particular y el proceso investigativo en general "va" con nosotras adentro (con nuestros miedos, nuestras inseguridades, nuestras confianzas, etc.). En este apartado presentamos algunos registros autorreflexivos. Relatar secuencias de nuestras experiencias migrantes/investigativas nos permite comprender ese lugar de disputa, permanente, entre el lugar incómodo y confortable en el que nos encontramos. Este registro no solo es una cantera de información e instancia analítica (Guber, 2014), sino también expresión de diferentes posicionamientos (políticos).

\section{Boliviana, ¿y qué?}

No pretendo hacer un acápite biográfico. Desde el relato en fragmentos de mi historia, en ciertas experiencias cotidianas que tensionan y disputan con mi formación académica, buscan el desafío de un tink $u^{11}$ entre mis experiencias y la construcción teórica.

Nací en la ciudad de Tarija, Bolivia; mi padre (1919) era quechua, de Punata, Cochabamba. Fue militar de profesión ${ }^{12}$, destinado a la región chaqueña en

11 Tinku, palabra quechua que significa 'encuentro de contrarios', se utiliza dentro del léxico cotidiano de la región andina de Bolivia para hacer llamados a diálogos o a encuentros. También representa una danza propia del norte Potosí; en este caso, la primera acepción del término es la que cuenta.

12 En la década de los cuarenta, los descendientes indígenas que habían accedido a la educación primaria tenían dos opciones para seguir ascendiendo en la escala social: ser curas o ser militares. 
la época de la posguerra del Chaco. Allí conoció a mí madre (1940), quien era de Puesto Uno, una comunidad guaraní en Villa Montes, Tarija (donde crecí). Ambos hablaban lenguas originarias ${ }^{13}$, pero (a sus hijos) no nos enseñaron el idioma, quizá como resultado de un proceso de mestizaje cultural, instalado desde la Colonia y reafirmado durante la nacionalización y la homogenización (Rivera Cusicanqui, 1996) en el Estado Boliviano.

Durante mi niñez y adolescencia escuché historias sobre familiares míos o de vecinos que se vinieron a vivir a Argentina; mi madre solía decir que "La gente se va para la Baporenda donde hay korepoti". Esta expresión, en guaraní y en español, significa 'La gente viaja a Argentina porque allí hay plata'. Solía contar historias de cómo sus hermanas vivieron a Jujuy y, luego, una de ellas vino a Córdoba. Incluso ella vivió unos años en esta ciudad, cuando era joven; sus recuerdos, tristes, evocan experiencias laborales de explotación y de un amor que no la terminó de aceptar por ser boliviana.

Al salir de la secundaria, fui a Cochabamba, para estudiar en la universidad. Posteriormente, con el afán de hacer un postgrado, reactivé lazos familiares ${ }^{14}$ en Córdoba, que fueron un soporte para dar los primeros pasos e impulsar diversas actividades al llegar a la ciudad. Ya en Córdoba, comencé a participar en la agrupación cultural Boliviana ${ }^{15}$, integrada por bolivianxs e hijxs de bolivianxs, donde bailamos Tink $u^{16}$. Pues, fui descubriendo la colectividad boliviana en Córdoba que, de cierta manera, está muy marcada por actividades alrededor de las danzas folklóricas vinculadas a festividades bolivianas ${ }^{17}$. Conecté con aquellos "lugares" en los que nos reunimos lxs bolivianxs, las ferias, la cancha, casas familiares, de alguna manera me sentía contenida en un colectivo.

Por otro lado, mis experiencias laborales me marcaron: al principio, trabajé en un call center. Allí, me llamaban despectivamente 'La boliviana'. Asimismo, cuando trabajé de niñera, sugerían que no le hablará mucho al niño, porque él repetía ciertas expresiones que eran no argentinas, como "tú", "jalar", "quieres", etc. Solían decir: "Eso es como otro idioma".

De mi familia, la tía (hermana de mi madre y quien ya falleció) y el tío (oriundo de Esmoraca, Potosí), quien vive en Córdoba hace más de sesenta años, han concebido hijos, nietos y bisnietos, de quienes mi hermana dice "que a ellos no los criaron como bolivianos" refiriéndose que no participan de las actividades

13 Hago esta impronta con referencia al ser indígena de mi familia - y mío, por supuesto.

14 En Bolivia, muchos tenemos parientes en alguna parte de Argentina, producto de migraciones anteriores.

15 Es una agrupación cultural, con más de veinte años de trayectoria, que organiza la representación del baile Tinkuy (que en quechua significa 'encuentro'). Se trata de una danza de origen autóctono del departamento de Potosí, Bolivia, y se presenta en diferentes eventos, tanto en aquellos organizados por la comunidad boliviana, como en algunas peñas o fiestas locales de Córdoba y otras provincias.

16 El Tinku es una danza autóctona que se baila como parte de un ritual a la Pachamama, en el norte de Potosí y en el sur de Oruro, en Bolivia. También se ejecuta como danza folclórica en diversas partes de Bolivia y el mundo.

17 Festividades cívicas como el Día de la Independencia, el carnaval y el Día de la Madre; fiestas religiosas como la Virgen de Urkupiña, Tata Bombori, Virgen de Guadalupe, Virgen de Copacabana, entre otras. 
o tradiciones, por otro lado, me animaría a pensar que fue más para evitar el efecto de la discriminación.

En lo académico, me anoté en la Maestría en Antropología y empecé a participar de un grupo de investigación sobre migraciones, desde donde comencé hacer lecturas en torno a dicha temática. A medida que pasaba las páginas, la literatura se acercaba a mi experiencia de vida, me sentía interpelada e incómoda por las categorías, por los modos en qué se realizaban los trabajos de campo, cómo nos nombran, nos sitúan, nos miran. Aprendí sobre migraciones desde distintos lugares (académicos, sociales, afectivos, folklóricos), y entendí que lxs bolivianxs reconstruimos formas de vivir Bolivia en Córdoba desde las danzas, las comidas, el folklore, los velos o capas que, de cierta forma, empañan relaciones estructurales.

Mis primeras interpelaciones transitaban entre "tantas idas y venidas ${ }^{18 "}$ lecturas, experiencias en el campo como en la vida cotidiana, rondaba una sencilla, pero al mismo muy compleja pregunta: “¿Por qué nos estudian tanto?" Y a estas alturas, algunos libros parecían proféticos para describir hábitos migrantes.

Dos años después gané la beca doctoral, y entonces sentí con mayor potencia ese lugar de los otros, los académicos, siendo parte del colectivo del "nosotros bolivianos", esa abigarrada y caleidoscópica (Rivera Cusicanqui, 1996) forma en la que nos constituimos. Recuerdo que una vez una profesora de la universidad expresó que el acceso al campo sería "más" fácil conmigo y facilitaría el camino al grupo de investigación. Quise suponer que, sin querer, naturalizó mi condición y la de los otros. Como si la bolivianidad, si es que existe algo que podríamos llamar así, y las experiencias migrantes fueran todas iguales.

De cierta forma, me interpelaba la idea de ser "la boliviana migrante" de la literatura científica, de los medios de comunicación, o de los textos de las organizaciones y los Estados. Sospecho de la Bolivia que se reproduce, que se muestra, la que se expresa en la idea del buen migrante.

Me animo a interpelar la categoría migrante en lo cotidiano, ese sin fin de relaciones que se arman entre paisanos y criollos ${ }^{19}$ en el que se vive una heterogénea red de vínculos y afectos y en algunos casos sostienen y encarnan las diferencias creadas por los Estados para justificar las clasificaciones de los grupos humanos y porque no invisibilizar los procesos del pasado (Rivera Silvia, 2010).

Sin dudas, investigar es una aventura que encarna muchos desafíos en nuestras propias interpelaciones. La apuesta se encamina al proceso reflexivo ante la producción de conocimiento.

18 Hago referencia a una canción del folclore popular de Tarija, cuyo compositor es el Sr. Nilo Soruco. Véase el video en el siguiente enlace: https://www.youtube.com/watch?v=1V6nP4263Ag 


\section{¿Segunda de qué? Entre el acá y el allá}

Nací en Córdoba; mi padre migró en los setenta de Lima a Córdoba y hasta la fecha reside en dicha ciudad capital. Para algunos intelectuales soy "segunda generación de migrante", pero ¿segunda de qué? Crecí en la misma ciudad donde nací, solo me he movilizado por viajes de turismo o por alguna estancia de investigación. Es decir, la mayor parte de mi historia transcurrió donde me crie.

Comparto la idea según la cual caracterizar a una población a partir de su filiación supone, de manera implícita o explícita, una biologización tácita (Sayad, citado en García, 2003). Si bien esto no tiene ningún sustento en el plano biológico, sí lo tiene en el del lenguaje. Este término fue desarrollado históricamente en pos de inferiorizar y estigmatizar a determinados grupos. La naturaleza, lo biológico, es la justificación más antigua y más fácil: "la coartada ideológica consiste en hacer desaparecer o bien tergiversar la historia" (Margulis, 1999, p. 41).

Todo parece indicar que cuando aludimos a la llamada 'segunda generación' estamos pensando en una segunda generación de inmigrantes, como se trasluce claramente cuando, invirtiendo los términos del sintagma, se habla de los "inmigrantes de segunda generación". Sin embargo, resulta trivial - por mucho que siga siendo necesario - recordar que la mayoría de esas personas nunca inmigró. (García, 2003, p. 28)

¿Segunda de qué? Somos dos hermanas: ella, parecida a la familia de mi madre, migrantes italianos. Yo, parecida a la familia de mi padre, de las sierras ayacuchanas y de la costa de Ica. Es significativa mi identificación hacia "lo peruano" y no hacía "lo italiano". Mi condición étnica moldeo mis sentimientos, me clasificaron y me clasifiqué, me sentí distinta, me opusieron y me opuse a los 'autóctonos'. Sin embargo, allá en Lima, visitando a mis abuelos y parientes, era 'la argentina'. Acá, 'la hija del peruano', o simplemente 'peruana' (en general, de forma despectiva).

Desde pequeña, la experiencia migratoria interpeló mi vida, desde las historias que contaba mi padre, los viajes anuales a Lima a visitar a la familia, etc. Mi condición étnica hizo el resto. Los señalamientos no se hicieron esperar en el transcurso de mi escolaridad. Como dice Moraga (1998), el sistema educativo trató de blanquearme. Mi intención era pasar desapercibida, pero cuanto más trataba de esconderme, más resaltaban mi "condición de peruana". Me sentía menos (me sentía y me hicieron sentir menos, no todos, pero sí la mayoría de las instituciones con las que me involucré).

Fue en los años en que entré a la universidad cuando comencé a encontrar herramientas para pensarme distinta. Puntualmente, en una clase de Taller de Investigación, tenía que definir un problema de investigación, que podría ser el puntapié inicial de mi tesis de licenciatura. No sabía qué hacer, me sentía alejada de todo. La profesora, al ver mi frustración, me propuso pensar en 
ideas que me interpelaran de algún modo. Pasaron algunos días y los tiempos apremiaban para la presentación del trabajo práctico al respecto. Y allí, por algo que no puedo explicar, pensé en las migraciones como el lugar desde donde hablar y, quizá, aportar algo.

Poco a poco, comencé mi pequeña trayectoria profesional en torno a las migraciones, en general, $\mathrm{y}$, por supuesto, a las migraciones peruanas, en particular ${ }^{20}$. Ese momento me definió. Y comencé de nuevo un camino de idas y vueltas, avances y retrocesos, no solo académicos/profesionales, sino también personales.

En mis investigaciones es en el trabajo de campo donde se tensionan y se ponen en juego dos modos de lo que podría denominar el "acá y el allá"21 (similar al “sí, pero no" de Zapata, 2014).

Primero, el acá y el allá del territorio: Al realizar las entrevistas para mi tesis doctoral (algo similar me sucedió en mi tesis de grado en sociología), los y las migrantes me relatan sus experiencias, me explican sobre distintos lugares, paisajes, comidas o bailes de Perú. Y llega siempre la misma pregunta: “conoces?”. Otros, me preguntan "¿sos peruana?" Generalmente, comento que he viajado en reiteradas oportunidades (una de las últimas veces estuve unos cuatro meses) y si es posible les digo que soy hija de peruano. Es significativo como cambian sus discursos - hasta su corporalidad -, empiezan, en algún punto, a incluirme en un nosotros, a diferencia de los autóctonos. Pero a su vez, me distinguen y me reconocen, en la mayoría de los casos, como argentina, como un otro.

Segundo, el acá y el allá de la distancia social: es decir, las diferencias que se comprenden entre las experiencias de "pertenecer" al campo académico, sus disputas y a cierta clase social y las urgencias, intereses, y deseos de los sujetos. Si bien, en parte, pueden incluirme en ese nosotros en oposición a los autóctonos, soy un otro, por lo general, por la posición que ellos creen que ocupo en el campo social (académica, profesional, de clase, etc.).

La autorreflexividad me permite poner en escena de modo abierto y confeso la figura del investigador en la definición de sí mismo y de los otros (Guber, 2014, p. 16). Pues parafraseando a Clifford: ¿Quién es una para decir, citar, argumentar e interpretar la vida de los demás? (Clifford, citado en Guber, 2014).

La posición radica en intentar saber/comprender y generar procedimientos de traducción. Apostar a "crear inteligibilidad sin destruir la diversidad" (De Sousa Santos, 2009, p. 101). El trabajo de traducción busca captar la relación hegemónica entre experiencias y lo que en estas hay más allá de dicha relación.

20 Nunca le agradecí a la profesora de dicha materia por esas palabras. Estoy segura de que ella no registró ese momento, que para mí fue crucial.

21 No es nuestra intención dicotomizar las experiencias, la distinción es solo analítica. 


\section{Conclusiones preliminares: nuestros desafíos, nuestras apuestas}

Presentamos diversas reflexiones del trabajo de campo, acompañadas de preguntas, de interpelaciones y de algunos desafíos de nuestras investigaciones. Este registro preliminar nos permite articular los procesos migratorios (propios y ajenos) con nuestras sendas investigativas, con especial atención a la autorreflexividad. Es decir, registrar y reflexionar el lugar que el investigador tiene en la producción de conocimiento. Al articular migración, investigación y autorreflexividad de un modo específico estamos definiendo nuestras posiciones y disposiciones (contingentes) en el campo académico.

Si bien comprendemos que las ciencias sociales han producido un distanciamiento "de las viejas y burdas" posturas que pretendían describir o explicar al otro bajo los criterios objetivos del conocimiento científico y de la relación dicotómica entre "sujeto/objeto", se ha avanzado poco en el reconocimiento del lugar que ocupan los investigadores en el proceso de construcción de conocimiento, pero menos aun se ha avanzado sobre los investigadores denominados halfies (como expresamos anteriormente el mayor aporte se encuentra en la antropología).

Nuestras inquietudes iníciales, la apuesta por unas categorías o herramientas teóricas y no otras, nuestras confesiones y experiencias migratorias pretenden aportar a estas discusiones. En este sentido, presentamos algunos lineamientos a favor de la autorreflexividad y la significatividad de dicha herramienta en las distintas disciplinas de las ciencias sociales, en pos de sortear ciertos avatares en el trabajo de campo y evaluar la presencia académica.

Comprendemos que la construcción de la investigación está en permanente reflexión, incluye un ir y venir, de múltiples interrogaciones, donde "necesariamente" hay que dejar registro al respecto, como un modo de vigilancia epistemológica (Bourdieu, 2005). Asimismo, implica reconocer cierto posicionamiento, pues es imposible "conocer desde ninguna parte y de parte de nadie" (Guber, 2014, p 28). Lejos de proveer y constituir miradas desinteresadas o neutrales, apostamos a construir, de forma analítica, mundos donde decidimos explorar, aventurando supuestos, y tomando decisiones al respecto.

La autorreflexividad nos permite comprendernos divididas (halfies). Sin esperar que desaparezcan estos acá/allá, sino reconocer y explicitar estas tensiones. Es necesario, a nuestro entender, explicitar este camino de autorreflexividad y alternancia, para sortear miradas naturalizadas y esencializadas. “Ni acá, ni allá: en tensión permanente, en aras de reflexionar y dejar registro sobre nuestras propias representaciones".

Sin embargo, comprendemos que "nuestra pertenencia" no garantiza que tengamos una mayor facilidad que los "otros académicos" para dar cuenta de los procesos que intentamos investigar. De lo contrario, solo estarían legitimados 
para hablar de ciertos grupos quienes pertenecen a ellos, y caeríamos en la idea esencialista de que en esos grupos todos los miembros comparten necesariamente las mismas posiciones sociales y los mismos marcos interpretativos ${ }^{22}$. De este modo, en muchos casos no conocemos el juego "concreto/urgente" de las prácticas que estamos analizando: no compartimos las experiencias vividas de ese lugar, ni las urgencias/necesidades de los sujetos (en palabras de Combessie, 2005, distancia social y simbólica).

Por otra parte, queda latente, más allá de los mecanismos de vigilancia y reflexividad, aquellas palabras de Spivack donde expresa que un sujeto puede "[...] 'habla[r]' físicamente; sin embargo, su 'habla' no adquiere estatus dialógico - en el sentido en que lo plantea Bakhtin (2003, p. 298) - , [...] no es un sujeto que ocupa una posición discursiva desde la que puede hablar o responder".

Quizá sea momento de abandonar la ilusión de "dar voz a los que no tienen voz". Los cientistas sociales no podemos hablar por otro (el migrante, el subalterno, etc.), ningún "teorizante intelectual puede representar 'a aquellos [que] actúan y luchan'” (Spivak, 2003: 300), pues, esto implica reforzar su posición subalterna y la opresión que se ejerce sobre ellos ${ }^{23}$.

Es posible que el punto de partida sea una apuesta por el "desaprendizaje", si esto fuera en algún modo posible, "articulando las distintas formaciones ideológicas - midiendo silencios, si fuese necesario- dentro del objeto de investigación" (Puwar, 2008, p. 259).

Nuestros desafíos están puestos en que la voz de los migrantes sea escuchada sin negar que esa voz, en este caso, será producto de interpretaciones y traducciones abiertas a los peligros antes expuestos: nuestra posición como académicas, como migrante e hija de migrante, desde la institución desde donde producimos, etc. No importa cuán afectuosas y éticas sean nuestras búsquedas, tenemos que mantenernos atentas no solo a las condiciones institucionales que las permiten (Puwar, 2008), sino también a las trayectorias de quienes investigan.

Sin certeza aún, y quizás sin buscarla, la clave teórica de Grignon y Passeron puede ser, a nuestro entender, una solución parcial y contingente a través del concepto de alternancia. Donde proponen alternar entre una mirada relativista y otra legitimista. Sin embargo, Garriga Zucal advierte que:

Agradecemos esta advertencia, y vigilancia (entre tantas otras observaciones), a Cynthia Pizarro.

23 Esto se conjuga con la categoría transparencia, propuesta por la autora: "los intelectuales [...] se vuelven transparentes en la competencia de relevos, ellos simplemente se informan sobre el sujeto no representado [el otro] y analizan — sin analizar - los trabajos del sujeto innombrado irreductiblemente presupuesto por el poder y el deseo. La 'transparencia' producida marca el lugar de 'interés'; se mantiene por la negación vehemente: 'Ahora este rol de árbitro, juez y testigo universal es uno que me rehúso absolutamente a adoptar'” (Spivak, 2003, p. 315). El saber científico, consciente o inconscientemente, se vuelve el único saber válido; los otros no tienen ni la validez ni el rigor del primero, por lo cual se produce un 'epistemicidio', es decir, la muerte (o la ausencia) no solo de los conocimientos alternativos, sino también de los sujetos de aquellos. Aquí no faltarán quienes desde la "tribuna académica" se sientan ofendidos y expongan que existen miles de producciones desde la sociología, la antropología, la ciencia política, etc. que exponen los saberes populares, indígenas, campesinos, urbanos, dándole 'voz a los que no tienen voces'. No negamos que esto sea así; más bien, lo que remarcamos de manera crítica son aquellas producciones que toman como unidad de análisis a ciertos sujetos sociales y los toman como dato para luego explicarlos. 
[... la] caricaturización de los legitimistas nos cabe a todos; nadie puede escapar totalmente del dominocentrismo, todos somos parte del mundo que analizamos y las estructuras de dominación están interiorizadas en las ciencias sociales de formas sutiles y burdas, pero interiorizadas como forma de ver el mundo. (2010, p. 6)

En este sentido, la alternancia apuesta a escapar al esencialismo analítico, entendiendo que los sentidos tienen una dimensión de aceptación de lo impuesto, al mismo tiempo que tienen un costado contestatario o de resistencia (es decir, no de pura sujeción).

Por lo tanto, reconocemos y comprendemos que la tarea académica se encuentra en constate tensión entre apuestas, disposiciones e intenciones que exceden el campo científico, con miras a trascender el dualismo entre el sujeto que investiga y el objeto investigado, sin olvidar o negar las diferencias y desigualdades entre las investigadoras y los grupos estudiados.

Tendremos que dar cuenta de esta singularidad constitutiva: conjugar nuestras subjetividades, enunciarnos en vigilancia frente a la amenaza de esencialismos y buscar dispositivos analíticos y críticos que nos permitan escapar de ellos.

\section{Referencias}

Albarracín, J. (2005). Inmigración en la Argentina moderna: ¿un matrimonio en la salud y en la enfermedad con los europeos? En E. Domenech (ed.), Migraciones contemporáneas y diversidad cultural en la Argentina (pp. 19-40). Córdoba: Centro de Estudios Avanzados de la Universidad Nacional de Córdoba.

Alvites Baiadera, A. P. (Mayo-septiembre de 2014). Los colores de las migraciones regionales. Miradas desde Argentina. Unidad Sociológica, (1), 34-41. Recuperado el 15 de septiembre de 2015 de http://issuu.com/ unidadsociologica/docs/unidad_sociologica_n_1

Benencia, R. (2008). Migrantes bolivianos en la periferia de ciudades argentinas: procesos y mecanismos tendientes a la conformación de territorios productivos y mercados de trabajo. En S. Novick (ed.), Las migraciones en América Latina (pp. 13-30). Buenos Aires: Catálogos Facultad Latinoamericana de Ciencias Sociales (Flacso).

Bourdieu, P. y Wacquant, L. (2005). Una invitación a la sociología reflexiva. Buenos Aires: Siglo xxI.

Bourdieu, P. (2010). Prefacio. En A. Sayad (ed.), La doble ausencia. De las ilusiones del emigrado a los padecimientos del inmigrado (pp. 13-17). Barcelona: Anthropos. 
Caggiano, S. (2007). Racismos y nación ante la inmigración. La percepción del 'otro', la cultura y los derechos en la producción de fronteras. Oficios Terrestres, (19), 10-23.

Canevaro, S. y Gavazzo, N. (2009). Corporalidades de la migración: performances e identificaciones bolivianas y peruanas en Buenos Aires. Revista Espaço Plural, 10(20), 31-40.

Colabella L. (2014). O te vamos a ir a buscar... Un caso de brujería en los límites de la observación participante. En R. Guber (ed.), Prácticas etnográficas. Ejercicios de reflexividad de antropólogas de campo (pp. 87-112). Buenos Aires: Instituto de Desarrollo Económico y Social (Ides), Miño y Dávila.

Combessie, J. C. (2005). El método en sociología. Córdoba: Ferreira.

De Genova, N., Mezzadra, S. y Pickles, J. (eds.) (2014). New keywords: Migration and borders. Cultural Studies. Recuperado el 10 de diciembre de 2015 de http://dx.doi.org/10.1080/09502386.2014.891630

De Sousa Santos, B. (2009). Una epistemología del sur: la reinvención del conocimiento y la emancipación social. Buenos Aires: Consejo Latinoamericano de Ciencias Sociales (Clacso), Siglo XXI.

Dinatale, M. (22 de junio de 2016). Otro reto para Macri: las fronteras perforadas. Diario La Nación.

Doménach, H. y Celton, D. (1995). La comunidad boliviana en Córdoba. Córdoba: Copiar.

Domenech, E. (Comp.) (2005). Migraciones contemporáneas y diversidad cultural en la Argentina. Córdoba: Centro de Estudios Avanzados, Universidad Nacional de Córdoba.

De Sousa Santos, B. (2009). Una epistemología del sur: la reinvención del conocimiento y la emancipación social. Buenos Aires: Consejo Latinoamericano de Ciencias Sociales (Clacso), Siglo XXI.

Echavarría Canto, L. (Abril de 2010). Corporalidad velada: la subjetivación del sujeto migrante. Revista Latinoamericana de Estudios sobre Cuerpos, Emociones y Sociedad, 2(2). Recuperado el 17 de septiembre de 2015 de http://www. relaces.com.ar/fullissue/RELACES-N2.pdf

Foucault, M. (2009). Poderes y estrategias. En Microfísica del Poder (pp. 163-174). Madrid: La Piqueta.

García, I. (2003). Los hijos de inmigrantes extranjeros como objeto de estudio de la sociología. Revista Andaluza de Ciencias Sociales, (3), 27-46. 
Garriga Zucal, J. (Enero-marzo de 2010). Una historia de franceses en la argentina, una perspectiva ilegítima sobre la cultura legítima. Questión. Revista Especializada en Periodismo y Comunicación, 1(25), 1-6.

Gil Araujo, S. (2009). Interrogar al Estado desde la inmigración. En E. Domenech (ed.), Migración y política: un Estado interrogado. Procesos actuales en Argentina y Sudamérica (pp. 13-20). Córdoba: Universidad Nacional de Córdoba.

Giorgis, M. (1998). La virgen prestamista. La fiesta de Urkupiña en el boliviano gran Córdoba. Córdoba: Antropofagia.

Grignon, C. y Passeron, J. (1991). Lo culto y lo popular. Miserabilismo y populismo en sociología y en literatura. Buenos Aires: Nueva Visión.

Guber, R. (2011). La etnografía. método, campo y reflexividad. Buenos Aires: Siglo xxI.

Guber, R. (2014). Prácticas etnográficas. Ejercicios de reflexividad de antropólogas de campo. Buenos Aires: Instituto de Desarrollo Económico y Social (IDES), Miño y Dávila.

Herrera, G., Carrillo, M. C. y Torres, A. (Eds.) (2005). La migración ecuatoriana. Transnacionalismo, redes e identidades. Quito: Facultad Latinoamericana de Ciencias Sociales.

Hinojosa Gordonava, A. R. (2009). Buscando la vida: familias bolivianas transnacionales en España. La Paz: Consejo Latinoamericano de Ciencias Sociales (Clacso), Fundación para la Investigación Estratégica en Bolivia (PIEB). Recuperado el 10 de diciembre de 2015 de http://bibliotecavirtual.clacso. org.ar/clacso/becas/20120418053427/lavida.pdf

Laime Ajacopa, T. (Ed.). (2002). Diccionario bilingüe. Iskay simipi yuyayk'ancha. Castellano-quechua, quechua-castellano. Bolivia: Centro Cultural Jayma.

Lander, E. (Comp.) (2005). La colonialidad del saber: eurocentrismo y ciencias sociales. Perspectivas latinoamericanas. Buenos Aires: Consejo Latinoamericano de Ciencias Sociales (Clacso).

Margulis, M. (1999). "La 'racialización' de las relaciones de clase". En M. Margulis y M. Urresti (eds.), La segregación negada. Cultura y discriminación social (pp. 37-62). Buenos Aires: Biblos.

Massey, D. S., Arango, J., Graeme H., Kouaouci, A., Pellegrino, A. y Taylor, J. E. (Julio-diciembre de 2008). Teorías de migración internacional: una revisión y aproximación. ReDCE, (10), pp. 435-478.

Mezzadra, S. (2008). Introducción. En Estudios poscoloniales. Ensayos fundamentales (pp. 15-32). Madrid: Traficantes de sueños. 
Mezzadra, S. (2005). Derecho a fuga. Migraciones, ciudadanía y globalización. Madrid: Traficantes de sueños.

Pizarro, C. (Junio de 2012). (Des)marcaciones de la bolivianidad en los hornos de ladrillos de dos localidades argentinas. Revista Temas de Antropología y Migración, (3), pp. 23-39.

Puwar, N. (2008). Poses y construcciones melodramáticas. En S. Mezzadra (ed.), Estudios postcoloniales. Ensayos fundamentales (pp. 237-260). Madrid: Traficantes de sueños.

Rivera Cusicanqui, S. (2010). Ch'ixinakax utxiwa: una reflexión sobre prácticas y discursos descolonizadores. Buenos Aires: Tinta Limón.

Rivera Cusicanqui, S. (1996). Bircholas. Trabajo de mujeres: explotación capitalista y opresión colonial entre las migrantes de La Paz y El Alto. Bolivia: Instituto Mama Huaco.

Sayad, A. (1984). Estado, nación e inmigración. El orden nacional ante el desafío de la inmigración. Apuntes de Investigación, (13), 102-116.

Sayad, A. (2010). La doble ausencia. De las ilusiones del emigrado a los padecimientos del inmigrado. Barcelona: Anthropos.

Spivack, G. C. (Enero-diciembre, 2003). Puede hablar el subalterno. Revista Colombiana de Antropología, 39, 297-364.

Tijoux, M. E. (2012). Peruanas inmigrantes en Santiago. Un arte cotidiano de la lucha por la vida. Polis (18). Recuperado el $1^{\circ}$ de enero de 2016 de http:// polis.revues.org/4185

Tsuda, T. (Julio de 1998). Ethnicity and the anthropologist: Negotiating identities. Anthropological Quarterly, 71(3), 107-124. Recuperado el 2 de febrero de 2016 de http://www.jstor.org/stable/3318081Accessed

Vasilachis de Gialdino, I. (2006). La investigación cualitativa. En Estrategias de investigación cualitativa (pp. 23-64). Barcelona: Gedisa.

Zapata, L. (2014). Ser y no ser indio/a mapuche. Pueblo indígena y diseminación. En R. Guber (ed.), Prácticas etnográficas. Ejercicios de reflexividad de antropólogas de campo (pp. 183-203). Buenos Aires: Instituto de Desarrollo Económico y Social (Ides), Miño y Dávila. 